\title{
Lockean Freedom and the Proviso's Appeal to Scientific Knowledge
}

\section{Introduction}

At the heart of any libertarian theory of justice lies its conception of how we appropriate rightful private property. And part of what makes the Lockean position so attractive is its proposal that the enough-and-asgood proviso - hereafter simply the proviso - successfully identifies each person's original fair share of the earth's material resources. By applying the proviso, each person, on her own, can determine her fair share of the natural resources. In this paper, I argue that Locke and contemporary Lockeans underestimate the problems involved in their frequent and implicit assumption that when we apply the proviso we use the latest scientific knowledge, whether of natural resources, technology, or the operations of the economy. Problematic for these theories is that so much of the pertinent knowledge used is obtained through some particular person's labor. If what is obtained through an individual's labor must be made available to everyone, and if any particular person's new knowledge affects the application of the proviso, then it seems that some will find themselves without freedom to pursue their own ends and others will find their freedom subject to the arbitrary will of others. Therefore, any interpretation of the proviso that employs the assumption of the latest scientific knowledge undermines the Lockean aim of arriving at a conception of freedom understood as the free interaction of equals subject to laws rather than to each other's arbitrary will.

Not recognizing the problems associated with assuming the latest scientific knowledge in the application of the proviso in Locke's own theory, many contemporary Lockean theories take this assumption on as their own when they attempt to revise the proviso in order to solve Locke's difficulty with original acquisition in conditions of scarcity. Indeed, they even exacerbate the problems by giving the need for the latest scientific knowledge a more central role to play. After providing an analysis of these issues as they appear in Locke's own theory, I address them as they also appear in the work of four prominent Lockeans: Robert Nozick, Michael Otsuka, A. John Simmons, and Gopal Sreenivasan. In the final sections of the paper, I try, albeit unsuccessfully, to overcome some of the

(C) Copyright 2010 by Social Theory and Practice, Vol. 36, No. 1 (January 2010) 
difficulty surrounding the need for scientific knowledge. The recalcitrance of the problems identified, however, leads me to conclude that finding solutions is essential to a Lockean conception of private property consistent with Lockean freedom.

\section{Locke's Proviso}

Locke's proviso concerns rightful relations between employable persons in their original acquisition of private property. The aim is to give an account of how unilateral acquisition of private property can be seen as acts of lawful freedom, understood as actions within the constraints of the laws of nature (II: 22, cf. I: 101). ${ }^{1}$ To be free is to act in accordance with the laws of nature, which in turn provide each person with a sphere in which he can set and pursue his own ends (II: 6, cf. II: 25, 56-59, 63). Ideally speaking, the state of nature is

a State of perfect Freedom to order their Actions ... within the bounds of the Law of Nature, without asking leave, or depending upon the Will of any other Man. A State also of Equality, wherein all the Power and Jurisdiction is reciprocal, no one having more than another ... [and no] Subordination or Subjection (II: 4, cf. II: 3, 6 f., 54 f., 61, 87, I: 67).

In the ideal version of the state of nature, people interact within the laws of nature in a condition of perfect freedom and equality devoid of subjection to each other's wills. It is a condition in which a person's natural power to set and pursue her own ends with her means is reciprocally restricted by the laws of nature rather than arbitrarily by other persons. And since, as Locke thinks, it is in principle possible for a virtuous person correctly to specify, apply, and enforce the laws of nature in her interactions with others, each person has a so-called "natural executive right," meaning a natural right to enforce the laws of nature when interacting with others (II: 6-9, 13).

Locke wants to give an account of private property appropriation that is consistent with this conception of freedom under laws, since only through private property do we have the means necessary to exercise our freedom. Locke aims to identify ideal restrictions upon private property appropriation that are consistent with both his conception of freedom under laws and each person's natural executive right. The restrictions on original property appropriation must therefore be determinable and enforceable by any person without thereby undermining anyone else's freedom. Determining such restrictions, however, gives rise to a puzzle

\footnotetext{
${ }^{1}$ Citations to Locke's Two Treatises of Government use the notation "I: 101" or "II: 22," e.g., to refer to the treatise and paragraph number. John Locke, Two Treatises of Government, ed. Peter Laslett (Cambridge: Cambridge University Press, 1998).
} 
for Locke, namely, how to reconcile two reasonable yet apparently incompatible claims concerning property. First, Locke argues, all land is originally owned in common, and second, an individual must be able rightfully to appropriate private property from the common land without consent from the other commoners (II: 25). How is unilateral private appropriation of any piece of property possible without thereby depriving others of their common land?

Locke's suggested solution to the puzzle is that by laboring on the commons, a person obtains a fixed property right in the appropriated resources given that he appropriates subject to certain restrictions. And the restriction we are concerned with here, the proviso, ${ }^{2}$ states that appropriation of natural resources is rightful (or gives rise to private property) at least if a person leaves "enough and as good" of the natural resources behind for others:

The Labour of his Body, and the Work of his Hands ... are properly his. Whatsoever then he removes out of the State that Nature hath provided, and left it in, he hath mixed his Labour with, and joyned to it something that is his own, and thereby makes it his Property. It being by him removed from the common state Nature placed it in, it hath by this labour something annexed to it, that excludes the common right of other Men. For this Labour being the unquestionable Property of the Labourer, no Man but he can have a right to what that is once joyned to, at least where there is enough, and as good left in common for others ... The labour that was mine, removing them [the natural resources] out of that common state they were in, hath fixed my Property in them (II: 27-28, cf. II: 25-35, 40-46, 50). ${ }^{3}$

Locke argues that to respect the proviso is to make sure that one interacts with others in a way that respects each able-bodied person's right to private property and to self-preservation through labor, and hence, does no "prejudice to any other Man" (II: 33, cf. II: 34, 36). By laboring on the land and leaving at least "enough and as good" behind, a person obtains "fixed" property in the natural resources, and others have an obligation to respect the rightfulness of his appropriation. ${ }^{4}$ Therefore, no able-bodied person can deprive another of resources appropriated according to the

\footnotetext{
${ }^{2}$ The other restrictions upon private property, namely, the waste restriction, the charity restriction, and the restriction governing the parental relation, are not relevant to the discussion in this paper. Also note that for the purposes of this paper, we do not need to go into all the interpretative puzzles concerning Locke's presentation of the labor argument. My aim is to avoid these textual controversies, since they are not important to the argument here.

${ }^{3}$ With the invention of money, this picture becomes more complicated, since consenting to the use of money is seen as implying consent to unequal possessions (II: 47-50). To engage the scholarship on this issue, though, is beyond the scope of this paper.

${ }^{4}$ One may read Locke as arguing not that everyone becomes obliged here, but that one does not wrong anyone if one uses coercion to protect the fair share of natural resources as determined by the proviso. Since the interpretation above is the more standard one and since this exegetical issue is inconsequential for the argument in this paper, I do not pursue this issue here.
} 
proviso without also wronging him, for that would be to deprive him of his labor.

\section{2.a. Problems concerning the application of Locke's proviso}

On Locke's account, a person labors subject to the proviso when she originally appropriates something from the commons. As long as the person at least leaves enough and as good of the natural resources behind, she has an enforceable right to the natural resources appropriated and to the values subsequently created by means of her labor. In this section, I will argue that because Locke implicitly assumes the latest scientific knowledge when applying the proviso, his argument encounters three problems: (1) it is irreconcilable with each person's equality, namely, the equal right to the fruits of one's labor; (2) it involves a rejection of each person's freedom, or right to choose which ends to pursue with her means; and (3) it gives particular individuals the right to change the way in which the proviso should be applied in particular circumstances, which is subjection to some particular person's will rather than to law. All of these problems illustrate a common problem: Locke does not have a conception of the application of the proviso that is consistent with his conception of equality and freedom under laws of nature rather than subjection to some particular person's will (cf. II: 4 above).

First, why can't Locke reconcile his implicit appeals to scientific knowledge with his defense of each person's equal right to the fruits of her labor? According to the proviso, our original appropriation is justified at least if we leave "enough and as good" behind of the natural resources for others. The problem arises because this conception of the proviso pays insufficient attention to the way in which knowledge determines what counts empirically as a natural resource. Consider Locke's own example, albeit from a different context, of the way in which the discovery of iron changed what were thought to be natural resources. ${ }^{5}$ Prior to our knowledge of iron, mountains were not seen as natural resources with respect to iron. But after the discovery, those mountains with iron became very valuable. The general point is that new scientific discoveries change the empirical question of what we are taking and what we are leaving behind, and so they also change the correct application of the proviso. To make sure that all appropriations are consistent with the changes in what constitute natural resources, it appears necessary to argue that Locke's proviso requires us to ensure that each scientific discovery is reflected in the application of the proviso. Therefore,

\footnotetext{
${ }^{5}$ See John Locke, An Essay Concerning Human Understanding, ed. Peter H. Nidditch (Oxford: Oxford University Press, 1985), book IV, chap. XII, §§10-11.
} 
from the point in time of the discovery of a new natural resource, there would be required new determinations of what satisfies the enough-andas-good restriction as well as readjustments of earlier appropriations in light of the new discovery. In short, the application of the proviso must accommodate the way in which scientific discoveries change not only the nature of current and future rightful appropriations, but also the rightfulness of all past appropriations. ${ }^{6}$

To make such an accommodation, Locke's account must explain how everyone either has or can acquire the required knowledge. Locke appears simply to assume that everyone already has it or at least has access to it at all times. But this assumption appears unjustifiable on his view, since the knowledge resulting from any scientific discovery presumably belongs to the person - say, the scientist-who discovered it. Since her knowledge is a result of her labor on her fair share of the natural resources, no one else can be seen as automatically having a right to it. Having such a right would be to have a right to the fruits of the scientist's labor. Thus, simply assuming the latest scientific knowledge when applying the proviso has the consequence that the conception of the proviso is inconsistent with protecting persons' "fixed" property in the values they create by means of labor on their fair share of the natural resources. ${ }^{7}$

Second, the appeal to knowledge when applying the proviso results in some individuals not having the right to do as they wish with their means, which is inconsistent with their right to freedom under laws. Those whose discoveries affect the application of the proviso would be required not only to instigate a redistribution of property, at least insofar as their new knowledge affects their own shares, but also they would be required to share their knowledge with others in order to bring about reassessments of fair shares and possible redistributions of what were once thought rightful original acquisitions. It makes little difference whether the burden is the weak requirement merely to make their knowledge available to others, or a stronger requirement to actually educate them. Regardless, an interpretation of the proviso that includes the knowledge assumption requires that those with knowledge must do something, namely, set ends, such that others have access to what they know. But then these specific individuals are no longer seen as having a right to choose which ends to set with their means, for their knowledge and labor must now be put toward meeting the particular end of making it possible for others to apply the

\footnotetext{
${ }^{6}$ Naturally, if we assume that the proviso does not regulate appropriations of the past in light of new scientific knowledge, then this latter point does not apply. I consider such a present-and-forward-looking conception of the proviso later in the paper.

${ }^{7}$ One alternative is to argue that we cannot be seen as having the right to the scientist's knowledge, though we must allow for our initial fair share to be adjusted in light of this knowledge. I return to this objection in the final sections of the paper.
} 
proviso. This problem has the strange implication that an individual cannot set an end to increase his knowledge of the world without thereby running the risk of undermining his own private property rights.

Third, the appeal to scientific knowledge to satisfy the proviso allows that those with knowledge are in a position arbitrarily to change the way in which the proviso is applied. By choosing one particular research program over another, a scientist can unilaterally and by mere choice (or "will") begin a process that might very well undermine the rightfulness of all current appropriations of various natural resources and land. For example, assume that before oil was discovered beneath the land, a particular geologist very interested in that possibility decides to do some research. After some time, she discovers huge oil deposits on some particular farmers' land. The proviso now appears to entail that due to the geologist's discovery, there must start a process leading to the reshuffling of land to give everyone, including herself, a fair share of the oil. In more sinister scenarios, the geologist may indeed have some foreshadowing of the possible consequences of her research, and thus solely on her own prerogative decide not to pursue it with regard to some parcels of land rather than others, say, those belonging to her friends and family. Because the scientist's knowledge provides her with such a favored position with regard to the application of the proviso, the rightfulness of other people's private property appears subjected to her will, rather than to laws that restrict everyone equally. ${ }^{8}$

\footnotetext{
${ }^{8}$ It is worth emphasizing that this is not merely an instance of the unobjectionable way in which people's choices affect how the laws of nature apply in particular circumstances. For example, if I choose to appropriate a particular piece of land, then this particular piece of land becomes unavailable to others. There are two differences between such a case and the case of the geologist. First, by means of her labor on her rightful share of resources, the geologist undermines another person's already appropriated piece of land. Second, the geologist is not merely applying the proviso (as in the case of merely appropriating and thus making a parcel of land unavailable to others), but by means of her labor on her fair share of the natural resources she is changing the way in which everyone must apply it. In addition, an anonymous referee has objected that this third argument is merely an instance of a more general problem. Because a person's physical and mental resources determine how useful objects are to her, someone with more resources would have the upper hand with regard to application. She can choose whether or not to make her strength and wit available to others and hence change both which things are useful to others and what must be left behind when they appropriate. The more general problem, so the objection goes, is that one person can determine the application of the proviso by choosing whether or not to withhold knowledge or other resources. I disagree with this objection. In my view, the general problem is the one I have identified, namely, that by choosing to labor on her own fair share of the natural resources one person can arbitrarily determine how the proviso must be applied by everyone. The reason is not that she chooses to share any of her resources with others, since this in principle cannot affect the correct application of the proviso. Rather, the reason is that her labor changes the "objective" nature of the answer to the question: what is the fair share of the natural resources?
} 
Finally, note that what is common to all three problems is that they undermine Locke's aim of giving an account of freedom in which we, as equals, can set and pursue our own ends constrained only by the laws of nature. This is precisely what the proviso, a principle intended to restrict everyone reciprocally, is supposed to ensure. But as we have seen, by making the latest scientific knowledge a prerequisite for the proper application of the proviso, the proviso becomes unable to do its work as a lawful restriction on individuals' original acquisition of property. The proviso does not protect everyone's equal right to the fruits of one's labor, it does not protect everyone's freedom to set and pursue one's own ends with one's means, and finally, its actual application can be arbitrarily affected by the will of some particular individuals. Therefore, Locke's theory of justice, with this theory of property as an essential component, has a significant internal tension.

\section{Contemporary Lockean Conceptions of the Proviso}

The above difficulties also characterize contemporary Lockean theories, because they assume that the appeal to the latest scientific knowledge when applying the proviso is unproblematic. In fact, it seems fair to argue that contemporary theories actually exacerbate the problems outlined above due to their increased emphasis and reliance on scientific knowledge to help Locke's proviso deal with issues of scarcity. To illustrate, let's take a look at four prominent, yet importantly different, contemporary Lockean theories.

\section{3.a. Robert Nozick's account of the proviso}

A primary aim of Nozick's Anarchy, State and Utopia ${ }^{9}$ is to overcome a problem concerning the operations of the proviso under conditions of

Her labor changes what constitutes a natural resource in the first place. This is why, in the bulk of the paper, I assume that scientists are not permitted to withhold their new knowledge; their knowledge is required in order to know what the fair share of resources for everyone is. In my example, the scientist's choice is whether or not to pursue knowledge - not whether or not to share it once obtained. Consequently, the general problem I have identified cannot be an instance of the general problem identified in the objection. (In response to the contemporary Lockean positions I discuss below, I also argue that if one's account of the proviso makes people dependent upon systems in order to acquire their fair share of the resources, then those in charge of the systems cannot withhold their knowledge of them. I agree with the referee that how to deal with personal differences regarding physical and mental capacities presents a special challenge to Lockeans, and to address this challenge I argue below that my account is successful also against Otsuka.)

${ }^{9}$ Robert Nozick, Anarchy, State, and Utopia (New York: Basic Books, 1974). All parenthetical page references in this section of the paper refer to this work. 
scarcity of natural resources. As Nozick understands it, "[t]he crucial point [of Locke's proviso] is whether appropriation of an unowned object worsens the situation of others" (175). He then argues (the famous "zipback" argument) that Locke's proviso is inconsistent with rightful, original acquisition in times of scarcity (176). As scarcity arises, the newcomer cannot appropriate a fair share, which entails that the person before him cannot have left enough and as good behind of the natural resources, and so on. This argument "zips back" because it applies to, and therefore undermines, all previous appropriations under conditions of scarcity (175 f.). Nozick's proffered solution is to soften the proviso while at the same time maintaining its central commitment that original appropriation must not leave others in a worsened condition. He suggests that a person may appropriate under conditions of scarcity if he compensates newcomers: "Someone whose appropriation otherwise would violate the proviso still may appropriate provided he compensates the others so that their situation is not thereby worsened; unless he does compensate these others, his appropriation will violate the proviso ... and will be an illegitimate one" (178). Compensation, Nozick suggests, can consist in either access to use the landowners' land or access to use or acquire some of the social product that landowners have produced upon their land. ${ }^{10}$ Moreover, Nozick argues that because the capitalist system produces a large social product, and because its markets give newcomers access to this social product through the market system, landowners' original appropriation of all the land is redeemed. Therefore, even though newcomers cannot appropriate land, because of the capitalist system they are not seen as left in a worsened condition.

Nozick emphasizes that in order to justify the claim that newcomers are not left "worse off," we must first settle what it means to be worse off. There needs to be established an "appropriate base line for comparison. Lockean appropriation makes people no worse off than they would be how?" (177). Unfortunately, Nozick does not fully answer this question, ${ }^{11}$ but in true Nozickean fashion, he does go on to say something about how we should calculate such a baseline. He suggests that were it possible to calculate the correct value of raw materials and the values created on the basis of the raw materials, then we could establish a base-

\footnotetext{
${ }^{10}$ Gopal Sreenivasan argues that Nozick's proviso captures Locke's actual conception of the proviso, since access to land or social product produced upon the land is also Locke's solution to problems arising with high levels of scarcity. See Gopal Sreenivasan, The Limits of Lockean Rights in Property (Oxford: Oxford University Press, 1995), p. 54. Because Nozick argues that his version of the proviso is (merely) "similar to the weaker of the ones we have attributed to Locke" (178, my emphasis), Nozick seems to believe he is offering a different proviso from Locke's own.

${ }^{11}$ As often is the case, Nozick simply says that the issue "needs more detailed investigation than we are able to give it here" (177).
} 
line for comparing whether or not persons are left worse off or better off with or without a capitalist system (ibid.). It is here that Nozick encounters the problems I have identified in Locke's proviso.

Nozick's utilization of the capitalist system to ameliorate the conditions of newcomers actually worsens the problems related to the need for the latest scientific knowledge when applying the proviso. He not only reproduces, but actually exacerbates, the first problem by implicitly giving scientific knowledge even more work to do in his theory. Special knowledge of the past and current value of the natural resources is necessary to calculate the baseline for determining whether or not someone is left in a worsened condition. Nozick relies on both correct historical knowledge of natural resources in addition to knowledge about the "social product" made available in markets to serve as compensation for newcomers. Yet in order to calculate the correct compensation, each person needs the most updated knowledge with regard to various social products and their values as determined by the markets. But then it seems that persons must have a right to the latest scientific knowledge of others in either the weaker (access to information) or stronger (right to be educated) sense. But as we have seen, such a right to the labor of another is irreconcilable with everyone having an equal right to the fruits of her own labor.

Nozick's position also reproduces the second problem. Those with knowledge, and only those, are required to pursue certain ends, since the pursuit of these ends is deemed required by the proviso. The knowledgeable are required to begin a reshuffling process and also to make their knowledge available to others in the stronger or weaker sense. Finally, Nozick's position encounters the third problem of subjecting all those without the pertinent knowledge to the will of those who have or who can easily obtain such knowledge. Again, the problem seems to be that those with knowledge are in a position arbitrarily to utilize what they know to undermine the rightfulness of current private property holdings. For example, depending on what kind of knowledge they already have, they may choose to pursue research concerning existing or new discoveries of raw materials, or they may opt for research programs that will lead to changes in the production, supply, and relative value of various social products. Therefore, those with the requisite knowledge and research capabilities will be able to determine how the proviso is applied in particular circumstances, since by having such knowledge they can affect what the particular circumstances are. In this way, they can subject others to their arbitrary choices with regard to how the proviso actually restricts current private property appropriations. That is to say, those who have such knowledge can by mere choice "unzip" the rightfulness of existing private property relations. Rather than being reciprocally restricted by the proviso as a "side constraint"-Nozick's term for a restriction 
consistent with freedom under the laws of nature-some people will have their freedom subjected to the will of others, namely, those in powerful positions with regard to knowledge.

\section{3.b. A. John Simmons's account of the proviso}

Despite the fact that Nozick and Simmons belong to the right-wing and the left-wing strands (respectively) of the Lockean libertarian tradition, they agree on the essential assumption that the proviso does not give everyone a right to land. Their essential difference, as we will see shortly, is that Simmons's proviso requires much more equality with regard to material resources than does Nozick's. Nevertheless, Simmons's proviso is even more reliant on the latest scientific discoveries than Nozick's, and consequently his position is more susceptible to the problem of ensuring free interaction as equals under laws rather than as subject to any particular person's will.

Simmons describes the situation in the state of nature prior to any private property appropriation as a "divisible positive community," meaning that all persons are seen as originally having an enforceable right to appropriate a fair share of the world's resources, though not any particular share (238, 281, 291 f.). ${ }^{12}$ Although Simmons shares Locke's "labour intuition," he sees labor not as a substance that one mixes with unowned goods, but rather as a purposive, intentional activity aimed at satisfying one's basic needs and obtaining some conveniences. The former he refers to as "self-preservation" and the latter as "self-governance" (27275). Therefore, labor is seen as giving rise to an original, natural, and enforceable right to particular goods, because it is necessary to secure our rights to self-preservation and self-governance (224 f., 236 f., 242). Simmons emphasizes that he wants to capture the "widespread or enduring intuition about property rights ... that labor in creating or improving a thing gives one special claim to it ... [so that] it would be wrong for others to take it away" (223, cf. 318 ff.).

Though Simmons agrees with Nozick that labor subject to the proviso yields only a "use right" to resources under conditions of scarcity, he goes farther by arguing that labor subject to the proviso must give rise to exclusive use rights or "exclusive property rights" in the "particular products" of one's labor (230 f., 248, 275). Use rights, argues Simmons, are sufficient for self-preservation, but not for self-governance, for a person cannot use her means to set and pursue her own ends (selfgovernance) if her use of these means is subject to the choices of others

\footnotetext{
${ }^{12}$ A. John Simmons, The Lockean Theory of Rights (Princeton: Princeton University Press, 1992). All parenthetical page references in this section of the paper refer to this work.
} 
(275 f.). ${ }^{13}$ Only the exclusive right to the fruits of our labor gives us independence from one another, since exclusivity gives us a right to "noninterference" with respect to the goods we have created with our fair share of resources (261 ff.).

How does Simmons deal with the problem of scarcity? Conditions of scarcity are seen as arising when it is no longer possible to leave behind enough and as good of the same kind of material. Under conditions of scarcity, the proviso is met if and only if newcomers can obtain

the opportunity of a living - a condition of nondependence, in which one is free to better oneself, govern one's own existence ... This requirement is ... consistent with one's being unable to appropriate [land and natural resources]. But it ... requires not only an unreduced level of material well-being, but independence and opportunity ... Each appropriation must simply leave enough and as good of the relevant goods in common for others, if there is no alternative way to secure the rights of others to self-preservation and self-government. The only relevant baseline is the condition of others prior to the appropriation. Appropriation must initially leave others with no less opportunity to exercise their rights (to a fair share) than they had before the appropriation took place (293 f., cf. 291 f., 298).

Under conditions of scarcity, then, those who have appropriated must provide newcomers with alternative ways to acquire the same level of material well-being and conditions of self-government as those who engaged in original appropriation enjoyed. Hence, Simmons has an answer to Nozick's "zip-back" problem. Unfortunately, Simmons does not tell us how we should calculate exactly what the proviso requires. Indeed, he believes that these practical problems of calculation may be "enormous, if not insuperable" (295). Nevertheless, Simmons maintains that his interpretation of the proviso results in "a theoretically clear (or clarifiable) limit on natural property rights, an objective measure of lawful accumulation" (294 f.), which is an amount that "preserves for each an opportunity for independence and self-government, not just self-preservation" (291, cf. 225, 284, 291-93). Simmons emphasizes that the proviso must operate similarly after the introduction of money (293 f., cf. 302-6). Therefore, the best Lockean position will not permit large, material (including monetary) inequalities insofar as these are incompatible with everyone obtaining reasonable opportunities for self-preservation and self-government (306, cf. 314-19, 321).

I believe that despite the great ingenuity and appeal of Simmons's position, he cannot avoid, and even suffers from more acutely than Nozick, the problems involved with an implicit need for the latest scientific knowledge in the correct application of the proviso. Simmons's reli-

\footnotetext{
${ }^{13}$ Since I am here only interested in engaging Simmons's theory, it is unnecessary to establish which interpretation, if either (Nozick's or Simmons's), actually captures Locke's own conception.
} 
ance on employment opportunities in the economy (especially a monetary economy) to secure independence (self-preservation and selfgovernment) makes his theory particularly vulnerable to the three charges leveled against Locke and Nozick. The reason is that so much knowledge is required. Employers and employees must know exactly what and how much they should exchange in order to fulfill the requirement of the proviso, namely, the guarantee of self-preservation and selfgovernance though labor. In addition, Simmons's proviso presupposes extensive knowledge of what constitutes a decent subsistence level of natural resources, including which particular material goods are required for subsistence. Moreover, it seems we would need considerable knowledge in order to pass judgment on what kind of life is "meaningful" or considered by particular people to be "worth living" - that is, with sufficient conveniences to enable self-governance. Finally, we would need a fairly extensive knowledge of markets and the fluctuating values of particular goods. Only such knowledge ensures that one's private property is reconcilable with everyone else's rights to self-preservation and selfgovernance. Furthermore, the theory calls for considerable knowledge concerning what work abilities are required to be fully independent in particular economic systems. As Simmons admits, calculations of this sort are "enormous, if not insuperable." But unlike Simmons, I believe that this is more than just a practical problem, since the proviso, in principle, presupposes that everyone at least has access to the relevant (latest) scientific knowledge. But as we have already seen, having access to the latest and evolving scientific knowledge built into the application of the proviso is in tension with central tenets of any Lockean theory.

The first problem, as we find it in Simmons's theory, is that those with knowledge are not secured an "exclusive" right to the fruits of their labor upon their fair share of resources. They must share their scientific discoveries and knowledge with others if interaction as subject to the proviso is to be possible. The second problem is that those with the pertinent knowledge are not given the right to set and pursue their own ends, which is necessary for "self-governance." For example, as the calculations satisfying the requirements of the proviso change with variances in economic conditions, those with the appropriate knowledge must initiate reshuffling processes and either satisfy the weak requirement by making their knowledge available to others or satisfy the strong requirement to actually educate them. Indeed, since the calculations are "enormous" and even perhaps "insuperable," and since the data used in these calculations presumably change nearly continuously as the markets fluctuate, or as new scientific discoveries are made, it seems fair to say that these redistribution and information/education projects would be ongoing. The third problem is that those in powerful positions with regard to knowledge can 
choose arbitrarily to set ends through which they can change the application of the proviso in particular circumstances by pursuing research that affects the value of currently available products in the market. Purely by their arbitrary choices they can therefore force a reshuffling of private property. Again, the granting of such power to knowledgeable persons with respect to the ownership of private property for all seems irreconcilable with the notion of being equally subjected to laws rather than to particular persons' choices or wills. In these cases, one particular group or person is seen as having the right to change the way in which the proviso is specified and applied in particular circumstances.

If I am right in thinking that Simmons's position runs aground on these three problems in the ways described, then it seems that his conception of the proviso faces even bigger challenges with respect to ensuring Lockean freedom than does Nozick's. Hence, though Simmons is more concerned than Nozick with securing for people exclusive property rights and self-governance under laws, having knowledge play such an important role in the application of the proviso actually serves to undermine securing those advances on Nozick's position.

\section{3.c. Gopal Sreenivasan's and Michael Otsuka's accounts of the proviso}

Gopal Sreenisvasan and Michael Otsuka reject Nozick's and Simmons's interpretations of the Lockean proviso since they do not secure everyone a right to land. ${ }^{14}$ Despite the clear advantages attaching to this aspect of Sreenivasan's and Otsuka's conceptions of the proviso, I will argue that their theories suffer even more acutely from the problems arising from presuming the latest scientific knowledge when applying the proviso.

Sreenivasan argues that if all persons start out with "the largest universalizable share of land," then the requirement of the proviso is met. The largest universalizable share, Sreenivasan argues, is calculated on the basis of the "comfort and support" (welfare) the various pieces of land can produce divided by the number of persons who have a right to appropriate a fair share of these resources. This calculation is a function of all the variables that influence the welfare that can be produced from the land, including the best available technology, fertility, and economic organization. $^{15}$

Michael Otsuka argues in a similar fashion. ${ }^{16}$ The main difference between Sreenivasan and Otsuka is that Otsuka includes the abilities of

\footnotetext{
${ }^{14}$ Since Michael Otsuka shares this basic assumption with Sreenivasan, I address relevant and contrasting aspects of Otsuka's theory as I go along.

${ }^{15}$ Sreenivasan, The Limits of Lockean Rights in Property, p. 117, including n. 54.

${ }^{16}$ Michael Otsuka, Libertarianism without Inequality (Oxford: Oxford University Press, 2003), pp. $30 \mathrm{ff}$.
} 
the persons appropriating the land as a relevant variable when calculating the welfare potential of the land. This difference entails that the disabled obtain a right to more valuable land than the able-bodied. Otsuka then argues that if we assume that persons have "normal" tastes, meaning that they also want luxuries, then by giving the disabled possession of the luxury goods, their rights can be secured through trade. He gives an example in which a majority of able-bodied persons and a minority of disabled persons inhabit an island. By giving the disabled persons control over the beaches (luxury goods) and the able-bodied the right to the farmland, "robust rights to self-ownership" can be secured for both parties. By robust rights to self-ownership, Otsuka means that both the ablebodied and the disabled can set and pursue ends without being forced to labor for others and also without any coercive redistribution, since both parties' rights can be secured through trade (farming products in exchange for access to beaches). ${ }^{17}$

Prima facie, these solutions seem preferable to those of Nozick and Simmons. Otsuka's and Sreenivasan's solutions not only give all persons a right to land, but they also tie the correct application of the proviso to something it is prima facie easy to measure empirically, namely, the total welfare potential of the land divided by the number of persons (with adjustments for the disabled, in Otsuka's theory). Nevertheless, since these theories include the strongest appeal to the latest scientific knowledge, they are subject to the three problems discussed above even more acutely than the others. First, having the welfare potential depend on the best available technology, fertility of the soil, the economic organization operative on the land, and people's individual abilities and normal tastes for luxury goods requires that everyone with a right to appropriate land must have a right to the updated information relevant to those calculations. But as we have seen in the other cases, having such a right conflicts with the right to the fruits of one's labor. Second, since anyone with new knowledge is required to act on it by instigating a reshuffling of the world's resources (at least as it affects her share) and to make her knowledge available to everyone else (strongly or weakly construed), she seems to have lost the right to set her own ends with her means.

Illustrating the third problem, why some individuals will end up subject to the arbitrary choices of others, requires a bit more of the theories. Again, assume that a geologist sets out to find and succeeds in discovering substantial oil reserves on the property of another-a farmer. This geological discovery multiplies the welfare that can be produced on the

\footnotetext{
${ }^{17}$ See Otsuka, Libertarianism without Inequality, pp. 32-34. Controversially, Otsuka claims that any additional costs required to secure the rights of disabled persons can come through fines charged against criminals for their wrongdoing (pp. 31-53).
} 
farmer's particular piece of land. In contrast to Locke, Sreenivasan's account does not entail that everyone has a right to some of the oil. Rather, the discovery must be taken into account when recalculating how the value of this particular piece of land influences the total welfare potential of land each person has a right to appropriate under the proviso. Under conditions of scarcity, with each new discovery of a resource, the "universalizable" share each person has a right to changes. Therefore, after the oil is discovered, through no choice of his own, the original landowner now has a right only to a very small piece of his former land-a piece presumably too small to make a living from farming. The rest of his land must be redistributed so as to provide everyone else with her recalculated largest universalizable share. Therefore, because the farmer does not have enough land left to continue farming, he must either go into the oil business or sell his land in order to buy a new tract of land. ${ }^{18}$ Hence, Sreenivasan's account also incurs the third problem of having one's right to set and pursue ends conditioned by the arbitrary choices of another.

In this particular case, the farmer's right to his private property and the values he has created on his land is seen as conditioned by what another particular person (the geologist) arbitrarily chooses to do with regard to his resources (research abilities). Because the geologist sets out to discover oil and actually does, the farmer must discontinue farming on his land. Of course, one can object by arguing that the farmer can simply sell his new share of land and purchase another tract of farmland. One might argue that even though this conception of the proviso entails that the farmer will have to start over (by rebuilding the farm on a new piece of land) each time a similar scenario occurs, this only shows a considerable practical inconvenience related to our rights to private property. On the contrary, I believe the objection underestimates the problems illustrated by the example. It seems that on this conception of the proviso, those who find ways to enhance the welfare potential of particular pieces of land are permitted to change the way in which the proviso applies. Because the application of the proviso requires the most updated scientific knowledge with regard to natural resources at any time, those without knowledge find their rights to property subject to the choices of those with it, rather than subject to laws. In fact, in this example, the geologist is permitted to determine, albeit temporarily, which particular means are available to the farmer, and thus to force the farmer to begin his farming

\footnotetext{
${ }^{18}$ It may be worth pointing out that the same method for calculating the welfare potential will be used to accommodate the rights of newcomers. For example, as newcomers arrive they can be given a piece of oil land that has the welfare potential equivalent to any other piece of land. If they have such a piece of land at their disposal, their rights to appropriation under the proviso have been fulfilled.
} 
project anew should the geologist decide to pursue his research plans. Since particular persons can obtain such power over others with respect to private property rights, it seems a stretch to say that the position enables a private sphere delineated by the laws of nature.

Similar problems seem to arise for Otsuka. In the well-known island example, Otsuka assumes that all the inhabitants arrive at the island at the same time. Assume that originally these consist in two able-bodied and two physically disabled persons. On Otsuka's theory, the disabled persons get the beaches, whereas the able-bodied persons get the farmland. Then assume that the two beach-owners spend much of their time doing scientific research. But instead of researching ways to help themselves overcome some of the physical challenges that result from their disabilities, they research ways to enhance the welfare potential of farmland. Perhaps they invent new tools that streamline and therefore increase production. Consequently, to account for the results of their research with respect to the welfare potential of the land, there are reshufflings of land in their favor, say, increased prices for access to the beaches. Alternatively, it could have been the farmers who set out to invent the tools that make it possible for the physically disabled to do some farming. In either case, it seems that by mere arbitrary choice, the participants can change how the proviso is applied-with the consequent reshuffling of land.

\section{An Attempt to Overcome the Problems Regarding the Application of the Proviso}

In this final part of the paper, I will try to overcome the three problems I have argued face currently available conceptions of the proviso. For considerations of space I will limit my efforts to Sreenivasan's account and to problems issuing from appeals to the latest available technology. It is reasonable, however, to argue that if we can reinterpret the notion of "available" technological knowledge such that we can calculate the welfare potential of land without invoking the problems above, then revised Lockean theories can probably avoid them.

One way to reinterpret the technology requirement is to argue that its correct application is determined by each person's actual technical knowledge, rather than by the best available technological knowledge, and to argue that it is each person's choice whether or not to act on her actual knowledge. Under these assumptions, the three problems seem to be avoided. No one obtains a right to anyone else's knowledge (labor), everyone is free to pursue her own ends with her means, and no one appears able to affect the application of the proviso to particular circumstances by mere choice. The fact that some persons have particular or 
more actual knowledge, or even a new technological insight, that affects the maximum welfare potential of a piece of land would no longer necessarily affect the welfare potential calculated under the provisions of the proviso. ${ }^{19}$ For example, the farmer in our example above can keep farming on the land even if the geologist discovers oil on the land, since the farmer does not have this knowledge. Knowledgeable persons also have sole discretion over whether or not they use their knowledge in relation to their fair share, though if they do want to use their knowledge, then their share of natural resources will be appropriately reduced. In our example above, if the farmer actually has the knowledge required and wants to use it to extract the oil from the ground, then his share should be appropriately reduced - otherwise not. Hence, we might think that under this conception of the proviso, Lockean freedom is intact.

An immediate problem now surfaces, however, in that most individuals cannot calculate their fair share of the resources, since they neither have nor can obtain the technological knowledge such a calculation requires. To calculate one's relative rightful proportion of land relative to everyone else's at all times, a person must have knowledge equal to everyone else, given that people actually want to use their knowledge. Hence, it seems that what progress we made with the new interpretation of the technology requirement (from best available to actual knowledge) is erased, since we have ended up with a conception according to which people can be subjected to restrictions whose correctness they cannot in principle evaluate. Since people do not have the right to the knowledge that justifies the restrictions applied, our theory has left them deprived of the possibility of knowing rightful from wrongful private property appropriations. To avoid this, we must argue that everyone has the right to all required technological knowledge and those with the knowledge must at the very least make it available, which reintroduces problems one (equal right to the fruits of one's labor) and two (freedom to set and pursue one's own ends). ${ }^{20}$ The proposal also fails to make any progress with

\footnotetext{
${ }^{19}$ It seems necessary to argue that those who happen to have knowledge only with regard to a particular kind of land that they do not themselves possess cannot be required to give up some of their own land, since they cannot utilize this knowledge. Similarly, they also do not get an automatic right to particular types of land simply because they have knowledge suitable to producing a great amount of welfare on the land. Only in this way can we avoid the problem of some persons' new knowledge leading to a reshuffling of land.

${ }^{20} \mathrm{We}$ might be tempted to respond to this objection by saying that rather than gaining the new knowledge himself, the ignorant person can appoint someone to calculate his fair share and thereby exercise his rights on his behalf. But this choice appears irrational in that it is an incoherent way for the ignorant person to exercise his rights. Exercising one's rights merely by authorizing another to do so for him is incoherent, because it involves a regress of authorizations. The ignorant person, due to his lack of knowledge, has no way of determining whether the person he appoints is exercising his rights correctly, either by
} 
regard to the third problem, since it seems that everyone is even further subjected to the arbitrary choices of knowledgeable persons. It seems not only that the rightful shares change each time people change their minds regarding whether or not to employ their knowledge to increase the welfare potential of their land, but the relative shares would change each time a person moves from inefficient to efficient uses of her land-and vice versa. This interpretation of the technology requirement implies that a person's fair share is subject to knowledgeable persons' changing opinions and even whimsical decisions concerning what they want to do with their land. Rather than enabling free interaction under laws, the proposed interpretation leaves everyone subject to the arbitrary wills of those with knowledge when it comes to the proviso's application. ${ }^{21}$

At this point, we may be tempted to resolve this problem by alleviating the need to reshuffle property in response to persons' varying degrees of new knowledge and decisions concerning how or whether to employ that knowledge. We could simply adopt the view that changes in knowledge do not give rise to a requirement to redistribute shares. Consequently, fair shares are calculated on the basis of the actual technical knowledge existing "at the beginning" or at the time of the first appropriation of fair shares. From then onward, new knowledge has no relevance to later calculations. Unfortunately, however, it is very problematic to disallow that new knowledge can initiate redistribution. On the one hand, we encounter a new type of problem, namely, one related to luck and power. The amount of natural resources one has a right to would now be largely dependent on luck - on whether future discoveries will enhance the welfare potential of the natural resources one has. Since such later discoveries do not trigger redistribution, it is merely a matter of chance who ends up with the better "fair" share as knowledge increases. Moreover, even in the scenario where only a few end up with the vast amount of the really valuable resources and so with much more eco-

calculating his fair share correctly or by acting in his real interests. The only solution seems to require the ignorant person to appoint a second person to monitor the actions of the first. But this of course requires him to authorize a third person to monitor the actions of the second, and so on. Therefore, this option presents an irrational choice, because it does not present a coherent way in which one exercises one's natural rights.

${ }^{21}$ It seems worth pointing out that this conception of the proviso also appears impossible to realize. To see this, imagine that many of the existing landowners have already switched into high-technology industries and therefore have little land at their disposal. Also assume that some newcomers arrive who have little knowledge and hence must be given a right to fairly substantial pieces of land. For considerations of space, it seems appropriate simply to say that reflecting upon this problem seems to lead to the conclusion not only that any attempt at solving this problem seems to reproduce the three problems considered throughout this paper, but it does not seem possible to conceive of this solution in such a way that it is reconcilable with everybody's right to be equal under the laws of nature. 
nomic power, this does not, in itself, give rise to problems of justice.

On the other hand, our three original problems also arise with this proposal, although in a slightly different form. Natural scientists are no longer the ones advantaged or disadvantaged. Rather, historians will play the pivotal role in the application of the proviso. Historians must employ their knowledge to figure out the status of technological knowledge "at the beginning" in order to fairly calculate the fair shares, and they must share their research and possibly educate others as to how correctly to apply the proviso. It might be tempting to argue that significant progress is made with respect to the third problem, that one person's research choices can arbitrarily determine what constitutes a fair share of the natural resources, since scientific discoveries can no longer initiate a reshuffling of current property distributions. But this is true only if there are no research discoveries in history, which is highly unlikely. Rather, it seems that if an historian sets out to challenge the "established" truth concerning what was known about a particular natural resource at the beginning of fair share appropriation, then her arbitrary choice of which research project to pursue would indeed determine the application of the proviso.

Certainly, it is possible to offer additional interpretations of the technology requirement. Hence, though the arguments given in this section do not together provide a conclusive refutation of contemporary Lockean conceptions of the proviso, I do believe they justify my claim that contemporary positions have yet to provide a conception of the application of the proviso that is consistent with their notion of Lockean freedom. On all the interpretations I have considered, the aim of the proviso is inconsistent with any reasonable application of it, because in each application it contradicts its very aim, namely, to enable free interaction as equals under laws rather than subjection to some particular person's will. Moreover, my suspicion is that any appeal to knowledge regarding the application will encounter the problems I have identified in some way or another. Since knowledge changes as a result of people's labor, it seems impossible to arrive at a stable conception of private property understood in terms of labor subject to the proviso. That is to say, Lockean freedom requires a conception of people freely setting and pursuing their own ends with their means as equals under law. Labor subject to the proviso aims to identify what their means are in the first place. Yet because knowledge is required to apply the proviso and since labor advances knowledge, the proviso cannot provide a stable restriction within which labor functions. Labor changes how the proviso is applied, and particular individuals choose what to invest their labor in. Consequently, the proviso cannot function as a restriction that enables freedom and equality under law rather than subjection to arbitrary choices. 


\section{Concluding Remarks}

Sreenivasan emphasizes that the proviso is meant as a sufficient, and not a necessary, requirement. ${ }^{22}$ This may reasonably be interpreted as meaning that insofar as it is empirically the case that all persons start out with the largest universalizable share, then the proviso is satisfied. We can see Sreenivasan as sharing this feature of his account with Locke, Nozick, and Simmons. Perhaps this is what Locke meant when he said that we satisfy the proviso "at least if" we leave enough and as good behind, because in so doing we do no "prejudice" to others when we appropriate. So if we interpret all the proposals for the proviso as a sufficient condition, then the proviso is seen as met if all persons as a matter of fact do enjoy a piece of land as required by it. Thus, we need not pay attention to how it came about that people determined their fair shares.

I disagree with this claim. The problems identified arise as the result of the proviso's application in the empirical world, and in that world our current knowledge grows by means of particular persons' labor. Moreover, the crucial point is that the proviso is the solution to Locke's original puzzle about private property: it is supposed to be an enforceable principle that enables an individual unilaterally to appropriate private property from the commons in a way reconcilable with the Lockean notion of lawful freedom. And only if everyone can actually apply and enforce the proviso is it reconcilable with Locke's claim that everyone has a natural executive right or a natural right to enforce the laws of nature. Hence, even if it happens to be the case that the proviso is fulfilled-say, because everyone happens to agree on how to fulfill it-Locke's original puzzle concerning private property would remain unsolved, since we have failed to explain an enforceable natural right to appropriate private property from the commons. ${ }^{23}$

$$
\begin{array}{r}
\text { Helga Varden } \\
\text { Department of Philosophy } \\
\text { University of Illinois at Urbana-Champaign } \\
\text { hvarden@illinois.edu }
\end{array}
$$

\footnotetext{
${ }^{22}$ Sreenivasan, The Limits of Lockean Rights in Property, p. 115.

${ }^{23}$ Thanks to Arnt Myrstad, Arthur Ripstein, Sergio Tenenbaum, Gopal Sreenivasan, and Shelley Weinberg for help with developing the ideas contained in this paper. Thanks also to Shelley Weinberg for her generous help in eradicating many infelicitous formulations.
} 
Copyright of Social Theory \& Practice is the property of Florida State University / Dept. of Philosophy and its content may not be copied or emailed to multiple sites or posted to a listserv without the copyright holder's express written permission. However, users may print, download, or email articles for individual use. 